\title{
The effect of RHIZOMA COPTIDIS and COPTIS CHINENSIS aqueous extract on radiation-induced skin injury in a rat model
}

Xi-Jing Wang ${ }^{1 \dagger}$, Shuai Lin ${ }^{1+}$, Hua-Feng Kang ${ }^{1}$, Zhi-Jun Dai ${ }^{1}$, Ming-Hua Bai ${ }^{1}$, Xiu-Long Ma ${ }^{1}$, Xiao-Bin Ma', Meng-jie Liư ${ }^{2}$, Xiao-Xu Liu' ${ }^{1}$ and Bao-Feng Wang ${ }^{1 *+}$

\begin{abstract}
Background: Radiation-induced skin injury is a common complication of radiotherapy. The RHIZOMA COPTIDIS and COPTIS CHINENSIS aqueous extract (RCE) can ameliorate radiation-induced skin injury in our clinical observation. But, the protective mechanism of RHIZOMA COPTIDIS and COPTIS CHINENSIS in radiation-induced skin injury remains unclear.

Methods: In this experiment, we developed a radiation-induced skin injury rat model to study the mechanism. The animals were randomly divided into control group, treatment group, radiation group, and treatment and radiation group. 5 rats in each group were separately executed on $2 \mathrm{~d}$ and $49 \mathrm{~d}$ post-radiation. The semi-quantitative skin injury score was used to measure skin reactions by unblinded observers, and hematoxylin and eosin staining was used to evaluate the damage areas by irradiation. The MDA content, SOD activity of skin and serum were measured to detect the oxidative stress.

Results: Acute skin reactions were caused by a single dose of 45 Gy of $\beta$-ray irradiation, and the skin injury could be found in all rats receiving irradiation based on the observation of HE staining of skin at different time-points, while RCE could significantly ameliorate those changes. The MDA content in serum and skin of control rats was $4.13 \pm 0.12 \mathrm{mmol} /$ $\mathrm{ml}$ and $4.95 \pm 0.35 \mathrm{mmol} / \mathrm{mg}$ prot on $2 \mathrm{~d}$ post-radiation. The rats receiving radiation showed an increased content of MDA $(5.54 \pm 0.21 \mathrm{mmol} / \mathrm{ml}$ and $7.10 \pm 0.32 \mathrm{mmol} / \mathrm{mgprot})$, while it was $4.57 \pm 0.21 \mathrm{mmol} / \mathrm{ml}$ and $5.95 \pm 0.24 \mathrm{mmol} /$ mgprot after treated with RCE ( $p<0.05)$. Similar changes of the MDA content could be seen on $49 \mathrm{~d}$ post-radiation. However, the SOD activity of rats receiving radiation decreased compared with control group on both time-points, which was inhibited by RCE ( $p$ < 0.05). Meanwhile, no valuable changes could be found between control group and treatment group on $2 \mathrm{~d}$ and $49 \mathrm{~d}$.
\end{abstract}

Conclusions: Our study provides evidences for the radioprotective role of RCE against radiation-induced skin damage in rats by modulating oxidative stress in skin, which may be a useful therapy for radiation-induced skin injury.

Keywords: RHIZOMA COPTIDIS, COPTIS CHINENSIS, Radiation, Skin injury

\section{Background}

Radiotherapy is a useful modality for cancer therapy, but ionizing radiation may injure surrounding normal tissues $[1,2]$. The effect of ionization caused by radiation can kill the tumor cell directly or indirectly by generating reactive oxygen species (ROS), free radicals (FR) to cure the disease.

\footnotetext{
* Correspondence: wangbf1680@126.com

${ }^{\dagger}$ Equal contributors

${ }^{1}$ Department of Oncology, the Second Affiliated Hospital of Xi'an Jiaotong University, Xi'an 710004, China

Full list of author information is available at the end of the article
}

The skin is primarily affected by the production of ROS and FR, release of inflammatory mediators/cytokines [3-5], and the skin may be significantly injured and its function profoundly impaired during radiation therapy [6,7]. Although we endeavor to maximize anti-cancer effects and minimize skin toxicity, radiation-induced skin injury is the most common complication of radiotherapy, with inflammatory damage caused by radiation on the skin, which may lead to treatment interruptions.

Under normal conditions, the deleterious effects of the free radicals are kept under check by the body defense

\section{Biomed Central}

(c) 2013 Wang et al.; licensee BioMed Central Ltd. This is an Open Access article distributed under the terms of the Creative Commons Attribution License (http://creativecommons.org/licenses/by/2.0), which permits unrestricted use, distribution, and reproduction in any medium, provided the original work is properly cited. 
system, the antioxidant system, which includes enzymes and antioxidants that prevent the commencement of oxidative damage and its propagation $[8,9]$. Ionizing radiation is known to induce oxidative stress through the generation of ROS and FR, thus resulting in the imbalance of the pro-oxidant and antioxidant in the cells, which can break the defense system [10]. The cell structures, including lipids, membranes, proteins and DNA, could be damaged by the overproduction of ROS generated from the interaction between radiation and water molecules in cells [11-14]. Polyunsaturated fatty acids, when exposed to ROS, can be oxidized to hydroperoxides that decompose to hydrocarbons and aldehydes such as malondialdehyde (MDA) [15]. MDA, itself, due to its high cytotoxicity and inhibitory action on protective enzymes, is suggested to act as a tumor promoter and a co-carcinogenic agent [16]. While superoxide dismutase (SOD), the antioxidant enzymes against oxidative damage, catalyzes the dismutation of superoxide anion into $\mathrm{H}_{2} \mathrm{O}_{2}$, which can clear away ROS. Then, $\mathrm{H}_{2} \mathrm{O}_{2}$ can be transformed into $\mathrm{H}_{2} \mathrm{O}$ and $\mathrm{O}_{2}$ by catalase. MDA and SOD are two important compounds in charge of the antioxidant system balance.

Now, the bottleneck of radiotherapy is not the lack of cancer-killing means, but the side effect of radiotherapy, which is difficult to overcome. Recently, although there are more and more researches of the protective mechanism of radiation-induced skin injury, the measures of clinical treatment depend mainly on anti-inflammatory, antioxidant [16-18] and cyto-protective, including using hormones, vitamins, Chinese medicine and removal of free radicals. But we are still lack of effective treatment to the radiation-induced skin injury.

RHIZOMA COPTIDIS has been reported to exert numbers of pharmacological effect, such as antibacterial [19], and antioxidative [20] and anti-inflammatory [21]. SOD can obviously increase in rats liver treated with COPTIS CHINENSIS aqueous extract, which acts as an anti-oxidant agent against CCL4-induced chronic oxidative stress [22]. COPTIS CHINENSIS shows strong free radical scavenging activity and stimulate immunity activities [23]. It can increase the expression of antioxidase isozyme induced by the short-time UV-B radiation [24].

The RCE, which is an aqueous extract from RHIZOMA COPTIDIS and COPTIS CHINENSIS, can ameliorate radiation-induced skin injury in our clinical observation. However, the protective mechanism of RCE in radiationinduced skin injury remains unclear. This study has been initiated to investigate the radioprotective effects of RCE on radiation-induced skin injury in rats.

\section{Methods}

Plant material and RCE

The RHIZOMA COPTIDIS and COPTIS CHINENSIS were bought from the traditional Chinese medicine LBX
Pharmarcy (Xian, China) and authenticated according to the descriptions found in the Chinese Pharmacopoeia [25] by $\mathrm{Dr}$ Sun in the Department of Traditional Chinese Medicine. The voucher samples, ZLK-ZY-07 (RHIZOMA COPTIDIS) and ZLK-ZY-13 (COPTIS CHINENSIS), were deposited at the Department of Oncology, the Second Affiliated Hospital of Xi'an Jiaotong University.

$15 \mathrm{~g}$ of RHIZOMA COPTIDIS and $15 \mathrm{~g}$ of COPTIS CHINENSIS were immersed in $800 \mathrm{~mL}$ distilled water. After being soaked for $30 \mathrm{~min}$, the RHIZOMA COPTIDIS and COPTIS CHINENSIS were boiled for 4 $\mathrm{h}$ by cease-fire. Then, we used a sterile gauze funnel to lead the liquid extracted into sterile bottles, stored at $4^{\circ} \mathrm{C}$ for use.

\section{Animals and treatment}

All animals were purchased from Experimental Animal Center of Xi'an Jiaotong University College of Medicine. The animals were housed and handled in strict accordance with the Guidelines of the Institutional and National Committees of Animal Use and Protection. The protocol was approved by the Committee on the Ethics of Animal Experiments of Xi'an Jiaotong University College of Medicine (Certificate No. 22-9601018). All efforts were made to minimize animals' suffering and to keep the numbers of animals used to a minimum. The animals were randomly divided into 4 groups: control group (C group), treatment group ( $\mathrm{T}$ group), radiation group ( $\mathrm{R}$ group), and treatment and radiation group $(\mathrm{R}+\mathrm{T}$ group). T group and $\mathrm{R}+\mathrm{T}$ group were treated with $2.5 \%$ RCE $\left(0.1 \mathrm{ml} / \mathrm{cm}^{2}\right)$ twice a day through applichating the area of radiation, $2 \mathrm{~d}$ pre-radiation. A single dose of 45 Gy was administered to the right buttock of each rat in $\mathrm{R}$ group and $\mathrm{R}+\mathrm{T}$ group at a dose rate of $1000 \mathrm{cGy} / \mathrm{min}$ using a $6 \mathrm{MeV}-\beta$ electronic beam of accelerator (Clinac 2100EX; Varian Medical Systems Inc, CA) at a distance of $100 \mathrm{~cm}$. The irradiated area was $3 \mathrm{~cm} \times 3 \mathrm{~cm}$, and the surrounding skin was covered with lead plate. A $1.0 \mathrm{~cm}$ tissue equivalent bolus was used to bring the maximal dose to the skin surface. 5 rats of each group were separately executed on $2 \mathrm{~d}$ and $49 \mathrm{~d}$ post-radiation and then the skin and blood samples were harvested for the assays of malondialdehyde (MDA), superoxide dismutase (SOD) according to the procedures described below. For histopathological study, part of skin was stored in formalin (10\%) before use.

\section{Skin scores}

Skin damage was assessed using Semi-quantitative Skin damage scores with scores of 1-5.5 (Table 1) based on previous acute skin damage models [26,27]. Skin damage was measured by unblinded observers approximately daily, and we evaluated it weekly. 
Table 1 Semi-quantitative Skin damage scores

\begin{tabular}{lc}
\hline SCORE & SKIN CHANGES \\
\hline 1.0 & No effect \\
\hline 1.5 & Minimal erythema, mild dry skin \\
\hline 2.0 & Moderate erythema, dry skin \\
\hline 2.5 & Marked erythema, dry desquamation \\
\hline 3.0 & Dry desquamation, minimal dry crusting \\
\hline 3.5 & Dry desquamation, dry crusting, superficial minimal scabbing \\
\hline 4.0 & Patchy moist desquamation, moderate scabbing \\
\hline 4.5 & Confluent moist desquamation, ulcers, large deep scabs \\
\hline 5.0 & Open wound, full thickness skin loss \\
\hline 5.5 & Necrosis \\
\hline
\end{tabular}

\section{Histopathological assessment}

For the histopathologic study, 5 rats of each group were separately executed on $2 \mathrm{~d}$ and $49 \mathrm{~d}$ post-radiation and the irradiated fields were obtained from buttock. The skin samples were fixed in $10 \%$ formalin. After routine processing, the skin samples were imbedded in paraffin wax. Four- $\mu \mathrm{m}$-thick slices were prepared and stained with hematoxylin and eosin for evaluation with light microscopy. Damaged areas were evaluated using damage (epidermal atrophy, dermal degeneration such as edema and collagen fiber loss, and hair follicle atrophy) percentages, which were scored on 5-points ordinal scale as follows: Grade $0=$ normal, Grade $1=$ minimal, Grade 2 = mild, Grade $3=$ moderate, Grade $4=$ marked, and Grade $5=$ severe. The methods were referred to previous studies $[28,29]$.

\section{Determination of lipid per oxidation}

Levels of MDA were determined as described by Yagi [30] with the colorimetric absorption of the thiobarbituric acid-malondialdehyde chromophore used to determine the index of lipid peroxidation.

\section{SOD activity measurement}

Activity of SOD was measured using a commercially available kit purchased from Nanjing Jiancheng BioEngineering (Nanjing, China). SOD activity measurement was based on the instructions of the colorimetric method.

\section{Statistical analysis}

All values were expressed as the mean \pm standard deviations (SD). Statistical analysis was performed with student's $t$-test using the statistical software SPSS 13.0. $\mathrm{P}<0.05$ was considered as statistically significant.

\section{Results}

\section{Skin scores}

The finding of minimal erythema began in 1 of 5 rats in radiation group ( $\mathrm{R}$ Group) in week 1 after irradiation.
All rats which had received irradiation showed the appearance of erythema together with desquamation on week 2 . In $R$ group, skin breakdown could be found in week 3 , with dry crusting and minimal scabbing. Patchy moist desquamation emerged in $R$ group in week 4, and then became confluent and enlarged few days later. $\mathrm{R}$ group had ulcers and large deep scabs in week 5, and continued to develop. In radiation and treatment group ( $\mathrm{R}+\mathrm{T}$ group), rats showed patchy moist desquamation in week 4 and ulcers in week 6 , without any progress later. The rats without irradiation showed no observed remarkable changes in the right buttock skin. Figure 1 showed the skin scores of $\mathrm{R}$ group and $\mathrm{R}+\mathrm{T}$ group at different stages.

\section{Histological hematoxylin and eosin (HE) staining results}

2 days after irradiation, insignificant differences of histopathological images were found between $\mathrm{C}$ group and $\mathrm{T}$ group as shown in Figure 2. Compared with those in $\mathrm{C}$ group, all the rats receiving irradiation showed significantly difference in epidermal cells swelling, especially in the spine layer and base layer, hair follicle epithelial cells swelling, collagen fiber edema, which led to arrangement disorder, and nucleus pycnosis. In $\mathrm{R}$ group, all those changes were great, compared with those in $\mathrm{R}+\mathrm{T}$ group, together with visible congestive vascular reactivity in dermis and subcutaneous tissue, inflammatory cell infiltration. The order of tissue damages in each group caused by irradiation was, as follows: $\mathrm{R}$ group $(3.6 \pm 0.55)>\mathrm{R}+\mathrm{T}$ group $(2.0 \pm 0.71)>\mathrm{T}$ group $=\mathrm{C}$ group $(0)$.

No significant differences were found in the histopathological images between $\mathrm{C}$ group and $\mathrm{T}$ group $49 \mathrm{~d}$ after irradiation. In $\mathrm{R}$ group rats, discontinuous dermal structures, with lots of nuclear pyknosis rupture, small amount of new capillaries, collagen

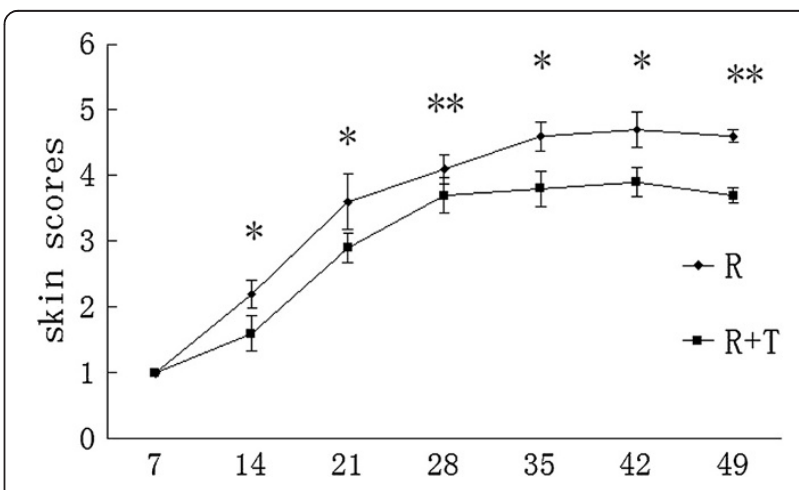

Figure 1 Skin scores in different time-points. The time courses of the skin scores after 45Gy of irradiation. All dates are presented as mean $\pm \mathrm{SD}$ in 5 rats. ${ }^{*} \mathrm{P}<0.05$, ${ }^{*} \mathrm{P}<0.01$. 


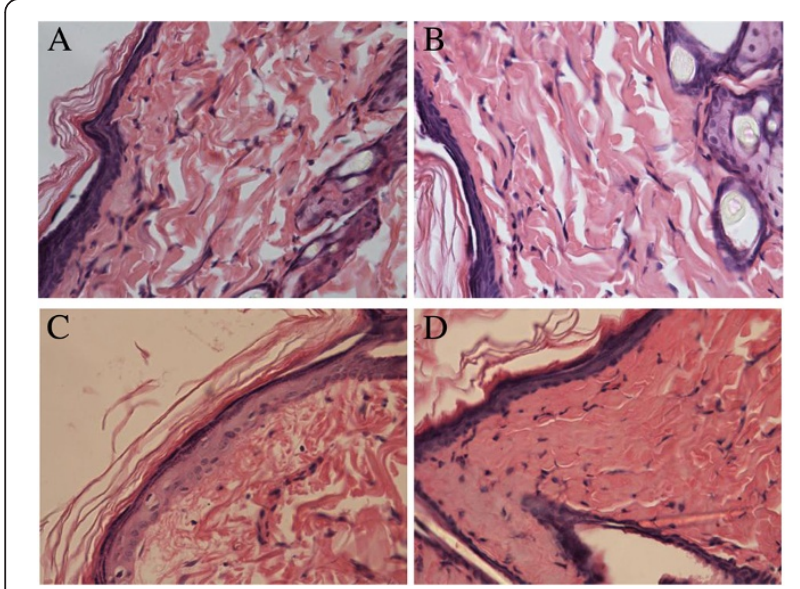

Figure 2 The histopathological images 2 days after irradiation in the present study. A and $\mathbf{B}$ : Normal histopathological images of the skin in the $\mathrm{C}$ group and $\mathrm{T}$ group. Epidermal, dermal structures and hair follicles were intact; $\mathbf{C}$ : Radiation injury of the skin in the $\mathrm{R}$ group. Epidermal cells and hair follicle epithelial cells swelling, nucleus pycnosis, collagen fiber edema, lead to arrangement disorder, together with congestive vascular reactivity and inflammatory cell infiltration could be found. D: Histopathological images of $\mathrm{R}+\mathrm{T}$ group, reflect a radioprotection against radiationinduced skin damage in terms of epidermal cells swelling, especially in the spine layer and base layer, hair follicle epithelial cells swelling, collagen fiber edema, and nucleus pycnosis. (HE $\times 400)$. fiber dissolution, disordered, inflammatory cells infiltration and few fibroblasts could be found. While in $\mathrm{R}+\mathrm{T}$ group, continuous dermal structures, lots of new capillaries, more fibroblasts could be observed, together with the lighter collagen fibers change and small numbers of inflammatory cells. The order of tissue damages caused by irradiation was as follows: $\mathrm{R}$ group $(4.8 \pm 0.45)>\mathrm{R}+\mathrm{T}$ group $(3.2 \pm 0.45)>\mathrm{T}$ group $=\mathrm{C}$ group $(0)$. Those changes are shown in Figure 3.

\section{Effects of RCE on Radiation-Induced MDA content in serum and skin}

The contents of MDA in serum and skin were $4.13 \pm$ $0.12 \mathrm{mmol} / \mathrm{l}$ and $4.95 \pm 0.35 \mathrm{mmol} / \mathrm{mgprot}$ in $\mathrm{C}$ group. No valuable changes were discovered in $\mathrm{T}$ group. The rats receiving radiation showed an increased content of MDA in skin and serum, inhibited by $\operatorname{RCE}(\mathrm{p}<0.05$, compared with that of $\mathrm{R}$ group). All data were given in Figure 4. It manifests that RCE may be useful for reducing the generation of MDA.

\section{Effects of RCE on the induction of radiation-induced antioxidant enzymes in serum and skin}

The SOD activity of $\mathrm{C}$ group in serum and skin were $566.16 \pm 15.11 \mathrm{U} / \mathrm{l}$ and $51.78 \pm 2.43 \mathrm{U} / \mathrm{mgprot}$ as shown in Figure 5 . No valuable changes could be found between

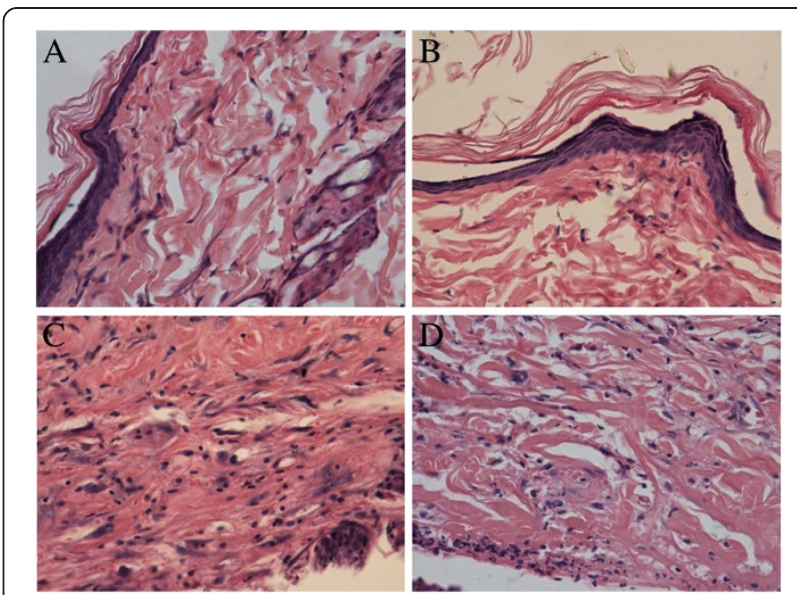

Figure 3 The histopathological images 49 days after irradiation. $\mathbf{A}$ and $\mathbf{B}$ : Normal histopathological images of the skin in the $\mathbf{C}$ group and T group; $\mathbf{C}$ : Radiation damage of the skin in the $\mathrm{R}$ group. discontinuous dermal structural, with lots of nuclear pyknosis rupture, small amount of new capillaries, collagen fiber dissolution, disordered, inflammatory cells infiltration and few fibroblasts could be found. D: Histopathological images of R $+\mathrm{T}$ group, reflect a radioprotection against radiation-induced skin damage in terms of continuous dermal structural, lots of new capillaries, more fibroblasts, the lighter collagen fibers change and little amount of inflammatory cells. (HE $\times 400)$.

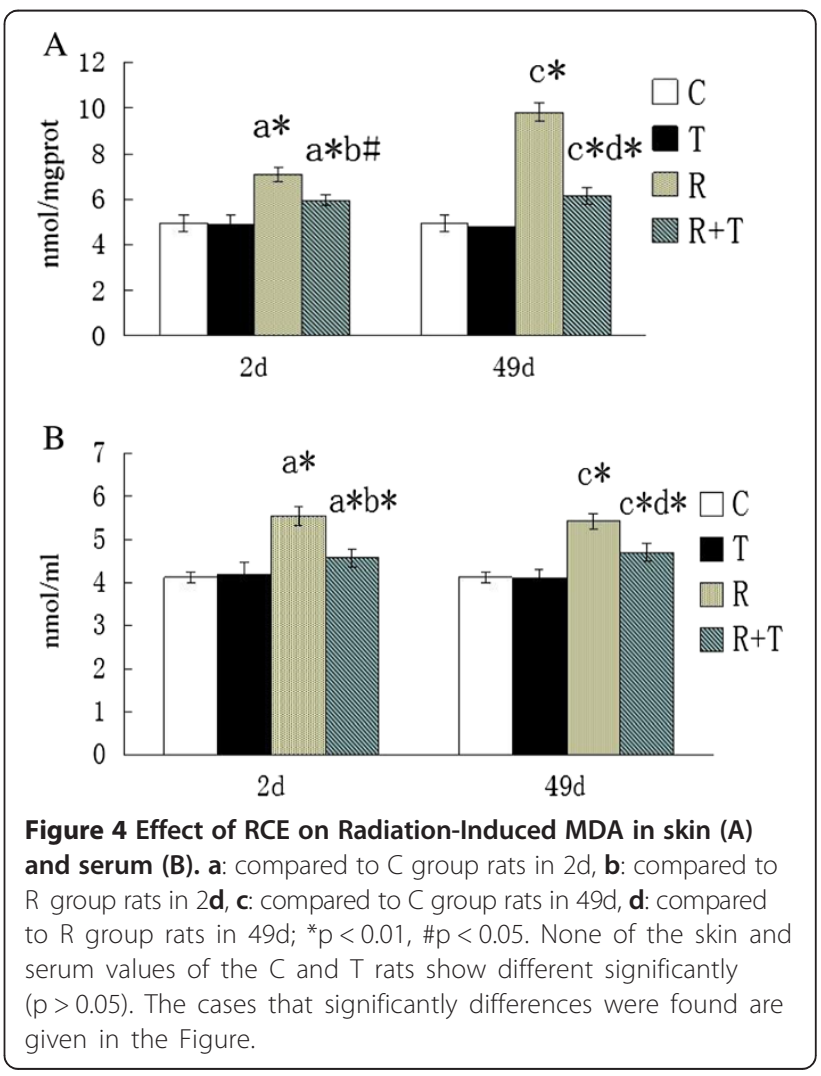




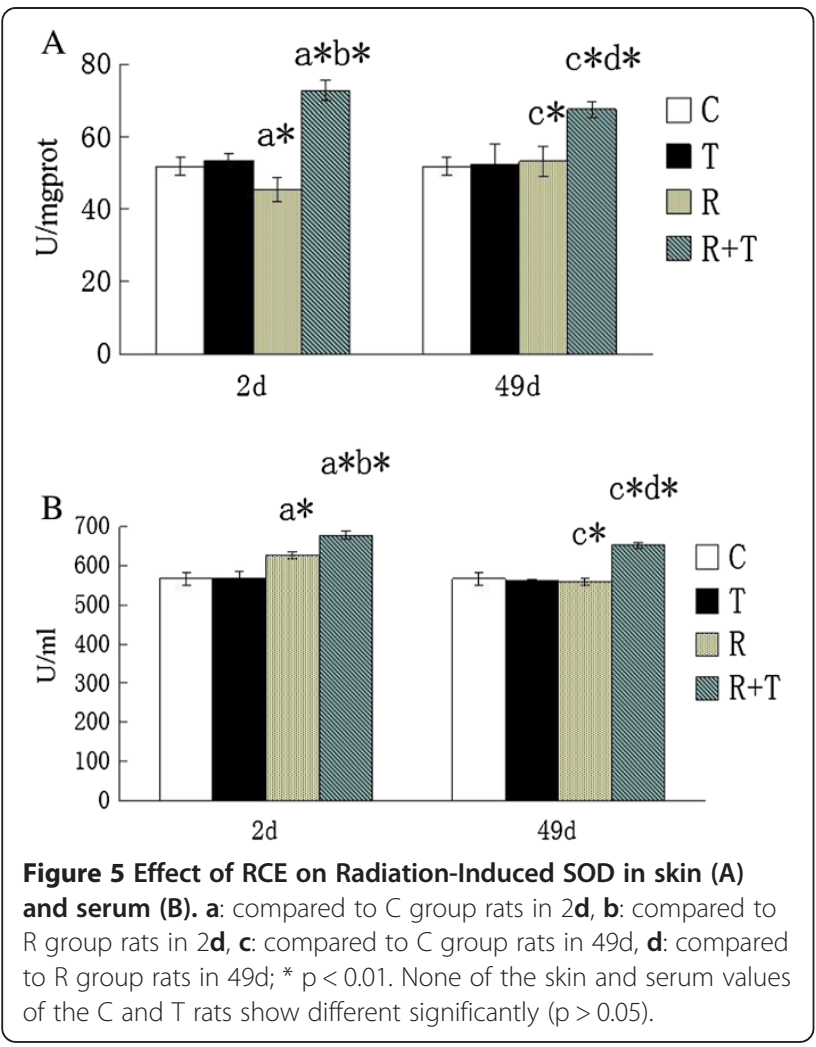

C group and T group. The skin SOD activity significantly reduced in rats receiving irradiation, compared with rats without irradiation. RCE could inhibit those changes ( $\mathrm{p}<0.05$ compared with that of $\mathrm{R}$ group). It indicates that RCE may be useful for scavenging oxygen-derived free radicals.

\section{Discussion}

In the present study, based on the observation of rats receiving a signal dose of 45 Gy of $\beta$-ray irradiation, acute skin reactions caused by ionizing radiation started developing on the 7th day post-irradiation in $\mathrm{R}$ group. RCE could ameliorate radiation-induced skin injury at different time-points, both in the skin scores and the appear time. As time went by, the protective effect became more predominant. Although RCE could decrease the square of skin injury, no significant difference was found between $\mathrm{R}$ group and $\mathrm{R}+\mathrm{T}$ group. The square of skin injury might be affected by the small numbers of rats, the exact area of radiation and the method of treatment. Through observation and HE staining, we found that the depth of skin injury in $R$ group was deeper than $\mathrm{R}+\mathrm{T}$ group. The radioprotective effect of RCE might be more related with the depth rather than with the square of skin injury, which needs further study.
HE staining showed the skin damage after irradiation, which was consistent with previous reports [28,31], while it was visible ameliorated after treated with RCE at different time-points. $49 \mathrm{~d}$ after irradiation, the rats in $\mathrm{R}+\mathrm{T}$ group showed more new capillaries and fibroblasts, which played an important role in the skin repair. We believe that RCE can ameliorate radiation-induced skin injury obviously.

MDA and SOD are two important compounds in charge of the antioxidant system balance. The increased MDA and decreased SOD levels can be found in the skin injury caused by irradiation [16]. At the same time-point in the irradiated animals, the marked radiation-induced decrease in SOD activity and rise in MDA content of skin were found in comparison with the controls, while the RCE could ameliorate those changes. A meaningful statistical analysis of SOD values were performed between groups $2 \mathrm{~d}$ and $49 \mathrm{~d}$ after irradiation, but no statistically significance was found in MDA content. ROS was generated from the interaction between radiation and water molecules, which could cause tissue injury. MDA could be produced from polyunsaturated fatty acids, when exposed to ROS [12]. RCE could ameliorate those changes. As time went by, SOD ceaselessly scavenged FR and ROS. MDA content and SOD activity did not change greatly, and tended to keep dynamic equilibrium in the regulation of internal environment. RCE might cause the phenomenon of no statistical significance in MDA at different time points through the increased SOD content, which could inhibit the production of MDA.

In serum, the increased content of MDA and the decreased content of SOD at different time points recorded in the present study are in agreement with those recorded by Sevil Kilciksiz [12], El-Missiry MA [16], which are inhibited by RCE. The skin exposed to radiation produces large amount of FR and ROS with the chain reaction, and the exchanges of oxidative stress can cause other tissue damage through circulatory system $[12,16]$.

In addition, no marked changes of SOD and MDA, together with the observation and HE staining, were found between $\mathrm{C}$ group and $\mathrm{T}$ group (Figure 4 and Figure 5) either in skin or in serum. Therefore, RCE is unharmful to rats and maybe a useful drug for radiation-induced skin injury.

\section{Conclusion}

The present study provides evidences for the radioprotective role of RCE against radiation-induced skin damage in rats by modulating oxidative stress in skin, which may be a useful therapy for radiation-induced skin injury. 


\section{Competing interests}

The authors declare that they have no competing interests.

\section{Authors' contributions}

WXJ, LS and WBF designed the research. BMH, MXL contributed to the animal experiments. LS, MXB and LMJ performed the biochemical and Histopathological experiments. KHF and LXX contributed to the reagents, and participated in its design and coordination. LS and DZJ analyzed the data; LS and WBF wrote the paper. Co-first authors: WXJ and LS. All authors have read and approved the final manuscript.

\section{Acknowledgments}

This study was supported by the Research Funds for the State Administration of Traditional Chinese Medicine of Shaanxi Province, China [NO. 72337DAOD2].

\section{Author details}

${ }^{1}$ Department of Oncology, the Second Affiliated Hospital of Xi'an Jiaotong University, Xi'an 710004, China. 'Department of Oncology, the First Affiliated Hospital of Xi'an Jiaotong University, Xi'an 710061, China.

Received: 27 January 2013 Accepted: 9 May 2013

Published: 15 May 2013

\section{References}

1. Huber R, Braselmann H, Geinitz H, Jaehnert I, Baumgartner A, Thamm R, Figel M, Molls M, Zitzelsberger H: Chromosomal radiosensitivity and acute radiation side effects after radiotherapy in tumour patients-a follow-up study. Radiat Oncol 2011, 6:32.

2. Sprung CN, Chao M, Leong T, MCKay MJ: Chromosomal radiosensitivity in two cell lineages derived from clinically radiosensitive cancer patients. Clin Cancer Res 2005, 11:6352-6358.

3. Bernstein EF, Sullivan FJ, Mitchell JB, Salomon GD, Glatstein E: Biology of chronic radiation effect on tissues and wound healing. Clin Plast Surg 1993, 20:435-453.

4. Kouvaris J, Kouloulias V, Kokakis J, Matsopoulos G, Myrsini B, Vlahos L: The cytoprotective effect of amifostine in acute radiation dermatitis: a retrospective analysis. Eur J Dermatol 2002, 12:458-462.

5. Azab KS, Mostafa AH, Ali EM, Abdel-Aziz MA: Cinnamon extract ameliorates ionizing radiation-induced cellular injury in rats. Ecotoxicol Environ Safety 2011, 74:2324-2329.

6. Simonen P, Hamilton C, Ferguson S, Ostwald P, O'Brien M, O'Brien P, Back $M$, Denham J: Do inflammatory processes contribute to radiation induced erythema observed in the skin of humans? Radiother Oncol 1998, 46:73-82.

7. Hymes SR, Strom EA, Fife C: Radiation dermatitis: clinical presentation, pathophysiology, and treatment 2006. J Am Acad Dermatol. 2006, 54:28-46.

8. Mansour $\mathrm{HH}$ : Protective role of carnitine ester against radiation-induced oxidative stress in rats. Pharmacol Res 2006, 54:165-171.

9. Juránek I, Bezek S: Controversy of free radical hypothesis: reactive oxygen species-cause or consequence of tissue injury? Gen Physiol Biophys 2005, 24:263-278.

10. Srinivasan M, Sudheer AR, Pillai KR, Kumar PR, Sudhakaran PR, Menon VP: Modulatory effects of curcumin on $\gamma$-radiation-induced cellular damage in primary culture of isolated rat hepatocytes. Environ Toxicol Pharmacol 2007, 24:98-105.

11. Watters D: Molecular mechanisms of ionizing radiation-induced apoptosis. Immunol Cell Biol 1999, 77:263-271.

12. Kilciksiz S, Demirel C, Erdal N, Gürgül $S$, Tamer $L$, Ayaz L, Ors Y: The effect of $\mathrm{N}$-acetylcysteine on biomarkers for radiation-induced oxidative damage in a rat model. Acta Med Okayama 2008, 62:403-409.

13. Valko M, Leibfritz D, Moncol J, Cronin MT, Mazur M, Telser J: Free radicals and antioxidants in normal physiological functions and human disease. Int J Biochem Cell Biol 2007, 39:44-84.

14. Flora SJ: Role of free radicals and antioxidants in health and disease. Cell Mol Biol (Noisy-le-grand). 2007, 53:1-2.

15. Mathews WR, Guido DM, Fisher MA, Jaeschke H: Lipid peroxidation as molecular mechanism of liver cell injury during reperfusion after ischemia. Free Radic Biol Med 1994, 16:763-770.
16. El-Missiry MA, Fayed TA, El-Sawy MR, El-Sayed AA: Ameliorative effect of melatonin against gamma-irradiation-induced oxidative stress and tissue injury. Ecotoxicol Environ Safety 2007, 66:278-286.

17. Sinha M, Das DK, Bhattacharjee S, Majumdar S, Dey S: Leaf Extract of Moringa oleifera Prevents lonizing Radiation-Induced Oxidative Stress in Mice. J Med Food 2011, 14:1167-1172.

18. Liu Y, Zhang H, Zhang L, Zhou Q, Wang X, Long J, Dong T, Zhao W: Antioxidant $\mathrm{N}$-acetylcysteine attenuates the acute liver injury caused by X-ray in mice. Eur J Pharmacol 2007, 575:142-148.

19. Kong WJ, Zhao YL, Xiao XH, Wang JB, Li HB, Li ZL, Jin C, Liu Y: Spectrumeffect relationships between ultra performance liquid chromatography fingerprints and anti-bacterial activities of Rhizoma coptidis. Anal Chim Acta 2009, 634:279-285.

20. Jung HA, Min BS, Yokozawa T, Lee JH, Kim YS, Choi JS: Anti-Alzheimer and antioxidant activities of Coptidis Rhizoma alkaloids. Biol Pharm Bull 2009, 32:1433-1438.

21. Kim JM, Jung HA, Choi JS, Lee NG: Identification of anti-inflammatory target genes of Rhizoma coptidis extract in lipopolysaccharide-stimulated RAW264.7 murine macrophage-like cells. J Ethnopharmacol 2010, 130:354-362.

22. Feng $Y$, Wang $N$, Ye X, Li H, Feng Y, Cheung F, Nagamatsu T: Hepatoprotective effect and its possible mechanism of Coptidis rhizoma aqueous extract on carbon tetrachloride-induced chronic liver hepatotoxicity in rats. J Ethnopharmacol 2011, 138:683-690.

23. Yan H, Sun X, Sun S, Wang S, Zhang J, Wang R, An P, Yang F, Kang W: Anti-ultraviolet radiation effects of Coptis chinensis and Phellodendron amurense glycans by immunomodulating and inhibiting oxidative injury. Int J Biol Macromol 2011, 48:720-725.

24. Wen Q, Zhang N, Cao RX, Zhou XY, Tang J, Wu NB: Response of isozyme and stress indexes of Coptis chinensis to UV-B radiation. Zhong Yao Cai 2012, 35:341-346.

25. Anon: Pharmacopoeia of The People's Republic of China. In Edited by 2010 Chinese. Beijing: China Medical Science Press; 2010:285-287.

26. Field SB, Law MP: The relationship between early and late radiation damage in rodents'skin. Int J Radiat Biol Relat Stud Phys Chem Med 1976, 30:557-564.

27. Kumar S, Kolozsvary A, Kohl R, Lu M, Brown S, Kim JH: Radiation-induced skin injury in the animal model of scleroderma: implications for post-radiotherapy fibrosis. Radiat Oncol 2008, 24:40.

28. Kitagawa J, Nasu M, Okumura H, Shibata A, Makino K, Terada H, Matsumoto S: Allopurinol Gel Mitigates Radiation-induced Mucositis and Dermatitis. $J$ Radiat Res 2008, 49:49-54.

29. Abe $Y$, Urano M: Fraction size-dependent acute skin reaction of mice after multiple twice-a-day doses. Int J Radiat Oncol Biol Phys 1990, 18:359-364.

30. Yagi K: A simple fluorometric assay for lipoperoxide in blood plasma. Biochem Med 1976, 15:212-216.

31. Ertekin MV, Tekin SB, Erdogan F, Karslioglu I, Gepdiremen A, Sezen O, Balci $E$, Gündogdu C: The effect of zinc sulphate in the prevention of radiation-induced dermatitis. J Radiat Res 2004, 45:543-548.

\section{doi:10.1186/1472-6882-13-105}

Cite this article as: Wang et al:: The effect of RHIZOMA COPTIDIS and COPTIS CHINENSIS aqueous extract on radiation-induced skin injury in a rat model. BMC Complementary and Alternative Medicine 2013 13:105.

\section{Submit your next manuscript to BioMed Central and take full advantage of:}

- Convenient online submission

- Thorough peer review

- No space constraints or color figure charges

- Immediate publication on acceptance

- Inclusion in PubMed, CAS, Scopus and Google Scholar

- Research which is freely available for redistribution 